\title{
O INFERNO DE DANTE: IMERSÃO E SENSORIALIDADE THE HELL OF DANTE: IMMERSION AND SENSORIALITY
}

\author{
Ana Paula Pinheiro da SILVEIRA ${ }^{1}$ \\ Universidade Tecnológica Federal do Paraná-UTFPR \\ apsilveira@utfpr.edu.br
}

Resumo. 0 presente artigo busca situar no panorama das reflexões sobre a leitura dos textos verbo visuais, uma proposta metodológica da narrativa Dante's Inferno, videogame produzido em 2010 pela empresa Visceral Games e inspirado na obra clássica de Dante Alighieri, A Divina Comédia. Baseando-se no constructo teórico da Semiótica Discursiva de linha francesa, e considerando a leitura como uma sucessão de eventos programados que podem ser analisados nos domínios da competência e da performance, conceitos caros ao universo semiótico, a análise permite compreender o fazer interpretativo do leitor em textos sincréticos, além de demostrar a importante discussão sobre as novas tecnologias como suporte para a leitura.

Palavras-chave: Semiótica: videogame; leitura

Abstract. The present article seeks to situate in the panorama of the reflections on the reading of the visual verbal texts, a methodological proposal of the narrative Dante 's Inferno, videogame produced in 2010 by the company Visceral Games and inspired in the classic work of Dante Alighieri, The Divine Comedy. Based on the theoretical construct of French Line Discursive Semiotics, and considering reading as a succession of programmed events that can be analyzed in the domains of competence and performance, concepts dear to the semiotic universe, the analysis allows us to understand the interpretive make of the reader in syncretic texts, in addition to demonstrating the important discussion about new technologies as a support for reading.

Keywords: Semiotics: videogame; reading

\section{Introdução}

Em maio de 2018 o jornal o globo divulgou a seguinte notícia "Disco dos Racionais MCs entra na lista do vestibular da Unicamp2". A novidade foi certamente provocada pelas mudanças tecnológicas que criaram a possibilidades de produzir textos valendo-se de multimodalidade e de multisemioses. 0 próprio site da Universidade de Campinas $^{3}$ justificava a inserção desse novo gênero com

\footnotetext{
1 Professora do Programa de Pós-Graduação em Estudos de Linguagens da Universidade Tecnológica Federal do Paraná (UTFPR), Campus Curitiba/PR - Brasil.. Doutora em Estudos da Linguagem pela Universidade Estadual de Londrina (UEL)

22 Seção Cultura, reportagem de Luccas Oliveira, disponível em:

$<$ https://oglobo.globo.com/cultura/musica/disco-dos-racionais-mcs-entra-na-lista-do-vestibularda-unicamp-22709241>

3 A notícia sobre a lista de obras para o vestibular 2020 encontra-se disponível em: < https://www.unicamp.br/unicamp/noticias/2018/05/24/unicamp-divulga-lista-de-obras-deleitura-obrigatoria-para-o-vestibular-2020>
} 
objetivo de ampliar o campo de leitura dos alunos e por possuírem relevância "estética, cultural e pedagógica" e indicava as plataformas Youtube e Spotify para acesso à playlist, uma mudança seja nos meios de circulação desses textos seja também na concepção da universidade que assume a relevância da cultura da periferia, até pouco tempo não reconhecida como canônica e distante da escola. Nesse contexto de mudanças Tecnológicas, músicas, clipes, filmes, Hqs, memes, videogames, gêneros produzidos em suporte digital, têm proporcionado a reflexão para estender o conceito de leitura já que, no momento atual, as telas ocupam um lugar antes destinado à cultura livresca e ao texto impresso.

Em face dessas grandes mudanças sociais e culturais que produzem novos modos de dizer, é necessário abrir espaços para a importante discussão de como propiciar a leitura desses novos gêneros e favorecer os letramentos necessários para que os alunos possam construir sentidos para estes textos.

\footnotetext{
[...] aqui, significa que compreender e produzir textos não se restringe ao trato do verbal oral e escrito, mas à capacidade de colocar-se em relação às diversas modalidades de linguagens - oral, escrita, imagem, imagem em movimento, gráficos, infográficos etc. - para delas tirar sentido (ROJO, 2004, p. 31).
}

Diante da necessidade de que o sujeito se posicione criticamente frente à sociedade e compreenda a relevância estética desses novos produtos culturais, aprofundar o conhecimento sobre a leitura de textos verbos visuais é condição basilar ao professor de Língua Portuguesa, no século XXI. Por esse motivo, esse estudo objetiva demostrar uma proposta teórica, baseada nos estudos desenvolvidos pela semiótica de linha francesa, para a leitura da adaptação de "A Divina Comédia, de Dante Alighieri para videogame.

0 estudo toma como texto base, a narrativa digital, Dante's Inferno, produzido pela Visceral Games no ano de 2010, inspirada na consagrada Obra de Alighieri e assume o audacioso projeto de tornar o inferno visível, por meio da imersão. Dante's Inferno leva-nos a uma viagem ao inferno, como avatar do jogo, guiado por Virgílio, poeta romano que escreveu, dentre outras obras, Geórgicas e a Eneida. Nesse percurso, o leitor-jogador encontra-se com a condenação da mente de Dante, presa em uma selva obscura, e com os monstros e as figuras mitológicas que influenciaram o trabalho de Alighieri, nos anos de 1300.

Os eventos primordiais para a compreensão da narrativa estão relacionadas ao triângulo amoroso (Dante/Betariz/Lúcifer). De forma resumida, a história tem 
início com o narrador em terceira pessoa e relata os acontecimentos do ano de 1191, uma referência aos ataques ingleses e franceses à cidade de Acre, no litoral da Terra Santa, a 48 km de Jerusalém, liderados pelo Rei Ricardo I da Inglaterra. Trata-se de uma luta que resultou no aprisionamento de 3000 civis para serem usados como reféns em troca de uma relíquia sagrada, em posse de Saladino, o curdo protetor da Terra Santa. A recusa de Saladino em negociar levou o Rei Ricardo a atacar e, consequentemente, gerou o massacre de milhares de prisioneiros, incluindo mulheres e crianças, como é muito bem representado no jogo, em cut-scenes ${ }^{4}$.

Beatriz é o grande amor de Dante, com quem pretendia casar-se antes de ingressar nas Cruzadas, em resposta ao pedido do bispo de sua cidade, para lutar por uma guerra santa, em troca do perdão dos pecados. Esse amor correspondido e, ao que tudo indicava, duradouro leva Beatriz a entregar-se a Dante antes da sua partida para as Cruzadas. A missão não é simples, o cruzado envolve-se em atrocidades, e o jogador vai descobrindo, aos poucos, a dualidade do caráter de Dante, envolvido em uma série de acontecimentos que culminam com a morte de Beatriz e a sua consequente ida para o inferno. Dante, arrependido e sentindo-se culpado vai ao inferno, a fim de salvar Beatriz de Lúcifer, mas, para isso, terá de viajar pelos 9 círculos do inferno- Limbo, Luxúria, Gula, Avareza, Ira, Heresia, Violência, Fraude e Traição - , lutar contra monstros terríveis, deparar-se com o seu passado e as suas culpas, envolver-se com um jogo duplo de Lúcifer, que não se interessa, realmente, por Beatriz, mas planeja a própria fuga do inferno.

Tomando como constructo teórico o Percurso Gerativo de Sentido e os estudos sobre o texto visual, percorre-se um caminho de leitura para esses principais eventos da narrativa, procurando demostrar como as categorias visuais imprimem e reiteram significados já presentes no texto.

\section{Caminhando pelo inferno: leitura e navegação.}

Fiorin (2009, p. 9-10), explicitando a importância do Percurso Gerativo de Sentido como um aparato metodológico defende:

\footnotetext{
${ }^{4}$ No final da década de 1980, os designers de jogos começaram a introduzir, na sua produção, uma sequência no jogo, não interativa, utilizada para avançar o enredo da história.
} 
Não basta recomendar que o aluno leia atentamente o texto muitas vezes, é preciso mostrar o que se deve observar nele. [...] A finalidade de um livro que apresenta uma gramática do discurso é tornar explícitos mecanismos implícitos da estruturação e interpretação de textos.

Utilizar o Percurso Gerativo de Sentido como um aparato metodológico é fornecer um instrumento para observar, no texto, como acontecem as relações discursivas, a organização dos seus percursos temáticos, figurativos, suas finalidades. Enfim, é dotar o leitor de um método que o ajude a indagar o que investigar no texto, a sua semiose, conforme esclarece Barros (2008, p. 83):

\begin{abstract}
A semiótica [...] procura hoje determinar o que o texto diz, como o diz, para que o faz. Em outras palavras, analisa os textos da história, da literatura, os discursos políticos e religiosos, os filmes e operetas, os quadrinhos e as conversas de todos os dias, para construir-lhes sentidos pelo exame acumulado de seus procedimentos e recuperar, no jogo da intertextualidade, a trama ou enredo da sociedade e da história. Se os estudos do texto buscam, em geral, os objetivos comuns do conhecimento do texto e do homem, a semiótica pode, quem sabe, somar a outros os passos que tem dado nesta direção.
\end{abstract}

Fica claro, portanto, que a "semiose" acontece dentro de um contexto maior do que o próprio texto, que as diversas vozes das formações ideológicas confirmam sentido ao discurso, refutando-o, ironizando-o, dialogando e atribuindo sentido a ele.

Na visão da Greimas (1979), o texto se manifesta na relação entre dois planos, o de conteúdo e o de expressão. Pietroforte (2009, p. 11) explica que "no plano de conteúdo, o sentido é gerado para se manifestar na expressão; no plano de expressão, o sistema semiótico se define, podendo ser de ordem fonológica, musical ou sincrética". O que ele quer dizer com isso é que, em semiótica, "se o sentido é gerado no texto, não há o 'que se diz' fora do 'como se diz', uma vez que os sentidos devem estar escritos no próprio texto e explicados por eles, na relação entre plano de conteúdo e plano de expressão.

Portanto, a semiótica vai conceber os sentidos na rede de relações entre o plano de conteúdo e plano de expressão. Os sentidos são gerados, no Percurso Gerativo de Sentido. Seguindo essa perspectiva, procura-se reconstruir as condições de produção por meio dos três níveis: fundamental, narrativo e discursivo.

Caracterizado por ser o mais simples e o mais abstrato, o nível fundamental demarca a gênese dos sentidos do texto, as oposições básicas, que permitem 
compreender a ideologia, o sistema de valores e a visão de mundo que subjazem ao discurso e aos aspectos da cultura.

Greimas (1970) formalizou um esquema clássico, o quadrado semiótico, por meio do qual é possível depreender as categorias binárias e estabelecer as relações semânticas que se opõem no texto.

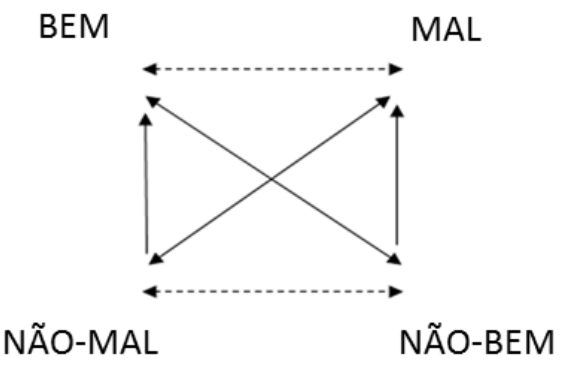

Figura 1: Quadrado Semiótico: bem vs. mal.

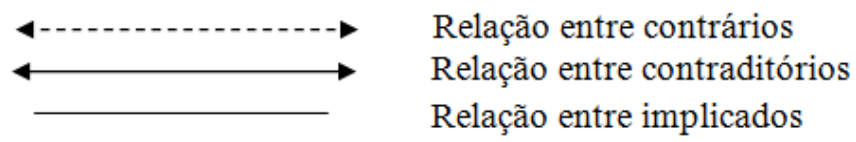

Nas palavras de Courtés (1979, p. 56, grifos do autor), Greimas, apoiado na linguística que o precedeu, vai analisar a substância do conteúdo com os procedimentos já existentes. Para isso, estabelece um método: "uma articulação do universo semântico em unidades mínimas de significação (= semas), correspondendo aos traços distintivos do plano de expressão (= femas)".

Para a semiótica greimasiana, os semas distinguem-se em dois tipos: os nucleares e os classemas. Os primeiros correspondem aos lexemas; os segundos “[...] manifestam-se em unidades sintáticas mais amplas que comportam a junção de dois lexemas, pelo menos" (GREIMAS, 1966, p. 103 apud COURTÉS, 1979, p. 58).

Na visão de Greimas (1966), os semas nucleares dizem respeito ao plano semiológico, enquanto os contextuais referem-se ao plano semântico e vão garantir, no texto, a hegemonia das isotopias. As relações que são estabelecidas no quadrado semiótico pertencem a um mesmo eixo semântico, são lexemas, que possuem semas comuns e, por isso, podem ser colocados no mesmo campo semântico. Cada um desses termos semânticos pode aparecer revestido da categoria tímica ou fórica, isto é, categorias de estado (eufórico ou disfórico). 
Categoria classemática, cuja denominação é motivada pelo sentido da palavra timia (cf. grego thymós, 'disposição afetiva fundamental'), a categoria tímica serve para articular o semantismo diretamente ligado à percepção que o homem tem de seu próprio corpo (GREIMAS; COURTÉS, 2008, p. 462).

Originada do grego euphoría corresponde à “[...] capacidade de sustentar, de tolerar algo com facilidade" (HOUAISS, 2009), portanto euforia e disforia são palavras que tendo recebido os prefixos "eu" e "dis", passam a significar "suportar com prazer" ou "sem prazer". De acordo com essa perspectiva, se um termo é visto como positivo dentro de uma determinada cultura, ou dentro da narrativa, por um enunciador, ele será considerado eufórico; se é visto como negativo, será concebido como disfórico.

Em Dante's Inferno, depreendem-se, diversas oposições semânticas. Entre elas, uma que permeia todo o jogo é o bem vs. o mal, sendo o primeiro uma categoria eufórica, e o segundo, disfórica. Um olhar pouco atento poderia estabelecer uma relação maniqueísta, relacionando Dante ao bem e Lúcifer ao mal. No entanto, mesmo se essa oposição é verdadeira e válida, estando na base do triângulo amoroso que conduz a trama (Dante/Beatriz/Lúcifer), por outro, no sujeito Dante, encontram-se as duas oposições, figurativizadas pelo uso das armas - a foice da morte, com ataques velozes e agressivos, que contrasta com a cruz de Beatriz, com ataques suaves e luminosos - e pela possibilidade de o jogador aumentar a pontuação, escolhendo absolver ou punir os condenados. Os upgrades alcançados com essas almas tornam-se, respectivamente, Dante mais piedoso (pontos sagrados), que libera novas habilidades para a cruz, ou impiedoso (pontos profanos), com habilidades para a foice.

A ideia dos designers de Dante's Inferno, como evidenciaram nos vídeos em que explicam a produção do videogame, era a de criar um grande efeito de imersão, para tornar visível o inferno. Isso é assegurado, desde o primeiro círculo, pelo plano de conteúdo - o título de cada fase indica o círculo do inferno em que estamos adentrando; os trechos do poema original de Dante estão presentes no videogame, escritos em quadros que surgem na tela, quando o jogador comete um erro ou entra em uma nova fase, ou nas falas das personagens Virgílio ou Dante bem como no seu plano visual - as pessoas são vomitadas no inferno, amontoadas, em uma relação opositiva de ordem vs. desordem, em que tudo exprime desarmonia, desfiguramento e deformação. 
A imersão, coadjuvada pelas cut-scenes, pode ser observada, no plano de expressão, por meio das categorias reiteradas pelas escolhas cromáticas, topológicas e eidéticas ${ }^{5}$, sendo que, em cada círculo, elas serão organizadas de modo a colocar em relevo os sentidos que pretendem expressar.

Em relação às categorias cromáticas, o inferno é construído privilegiando a oposição de claro vs. escuro, o que resulta na ideia de luz vs. trevas. Nesse inframundo, a luz é negada aos danados, que em vida escolheram o caminho das trevas e, por isso, são condenados a viver na escuridão.

O jogador é convocado a fazer uma experiência sinestésica, como elucida Teixeira (2009, p. 51-52) sobre o texto sincrético: "não se trata aqui de sinestesia metafórica, de um 'como se'. Trata-se da sinestesia experienciada como vivência própria do corpo. Essa imersão do sujeito na sensorialidade abre caminho para o conhecimento".

Nesse sentido, a visão do jogador, imerso na penumbra, é limitada, seja pela ausência de luz seja pelo afunilamento resultante da visão clássica do inferno, como um cone girado ao contrário, que constrange o jogador a aguçar os sentidos da audição, que de algum modo vai guiá-lo. No plano fônico, há o entrecruzamento de gritos, lamentos que se sobrepõem, do som da chuva e do vento, que convergem para a oposição de esperança vs. desesperança.

O desespero dos danados é expresso, ainda, pela relação eidética, a oposição curvo vs. retilíneo, presente na organização em círculos, que reitera uma temporalidade mítica e a impossibilidade de quebra do ciclo, pois não se pode voltar atrás, ou seja, os condenados são fadados a permanecer ali eternamente, por isso há a desesperança.

O curvo ressalta, também, a deformação, o grotesco e o horror nos monstros, guardiões de cada círculo.

Da análise topológica depreende-se uma oposição entre alto vs. baixo, porque o inferno localiza-se abaixo ${ }^{6}$. No videogame, o movimento de descida, ascendência $v s$. descendência, é marcado por uma maior intensidade, resultado de uma oposição entre aceleração vs. desaceleração: na medida em que Dante se

\footnotetext{
${ }^{5}$ As características aqui apontadas são de caráter geral, relacionadas às oposições bem vs. mal, céu vs. inferno, que permeiam todo o jogo. Existem outras que poderiam ser evidenciadas a partir de cada fase, mas não é possível ser analisada dentro do espaço de um artigo.

${ }^{6}$ Lúcifer, ao ser deposto do paraíso, cai das esferas superiores.
} 
desloca para a parte inferior, há uma aceleração do jogo, seus movimentos devem ser mais rápidos, não pode "vacilar" nas escolhas das armas, dos golpes, senão será vencido pelo inimigo. As criaturas que Dante encontrou em cada fase surgem e atacam-no contemporaneamente. Isso vai exigir uma maior habilidade do jogador, como sujeito debreado, um maior ajustamento para encontrar o seu estilo de jogar, realizando as ações em consonância com a programação do jogo.

Quanto mais se vai em direção ao inferno, em um deslocamento de cima para baixo, mais escuro é o fosso, menor é a luminosidade, mais profundo e estreito é o espaço em que Dante está para realizar seus movimentos.

Além disso, a oposição topológica marca, de um lado, alto, o Limbo, lugar onde permanecem os condenados sem culpa, os que não conheceram a verdade, e, do outro, baixo, o círculo da Fraude, Judeca, a morada de Lúcifer, aquele que negou e rebelou-se contra a verdade. Outro aspecto importante é que o Limbo é marcado pelo fogo, e Judeca, pelo gelo, um frio que queima, intensificado pelo sopro dos gigantes que traíram Júpiter.

Não se pode deixar de sublinhar, ainda, como oposição fundamental, a relação repouso vs. movimento, uma vez que, sem movimento, não há jogo. É por meio dos movimentos do jogador que o plano de expressão do jogo é alterado, que os sentidos são encadeados e gerados. Eles existem enquanto possibilidade, estão programados, mas dependem da performance do jogador, das suas escolhas dentro do jogo, para que sejam materializados no plano de expressão do texto.

Fase intermediária do Percurso Gerativo de Sentido, o nível narrativo é o momento em que se coloca em discurso a narratividade, como esclarece Fiorin (2009). Todos os textos possuem narratividade, que é “[...] a transformação situada entre dois estados sucessivos e diferentes" (FIORIN, 2009, p. 27).

A sintaxe narrativa se organiza em torno de dois actantes: o sujeito e o objeto de valor. De forma resumida, o sujeito é um papel actancial, um lugar que ele ocupa dentro do programa narrativo relacionado à busca de um objeto de valor, os anseios do sujeito. Conforme explica Barros (2008, p. 16), a narratividade é vista "[...] como um espetáculo que simula o fazer do homem que transforma o mundo".

O objeto de valor modal é o dever, o querer, o poder e o saber, que modalizam ou modificam a relação do sujeito com o seu objeto de valor. Em 
relação ao objeto que estamos analisando, Dante deseja salvar Beatriz, ele tem um "querer", e esse seu desejo será investido não só do "querer", mas também do "poder", do "saber" e do "dever". Nem sempre o objeto desejado está investido de tantos valores modais, embora, neste caso específico, isso aconteça.

Para entrar em conjunção com o seu objeto de valor, Dante deverá cumprir uma série de programas narrativos. 0 seu programa narrativo principal é "salvar Beatriz", os outros decorrem da necessidade de realizar, cumprir a sua performance para entrar em conjunção com o seu objeto de valor. São programas narrativos de uso, que se encontram hierarquicamente organizados, dispostos em relação hipotáxica, uma vez que a realização do segundo depende do primeiro, e assim sucessivamente. Por exemplo, para adentrar no primeiro círculo, o Limbo, deve atravessar o Rio Aqueronte e passar pelos portões do inferno, limite que divide os vivos dos mortos. Nesse sentido, deverá manipular (oferece-se como troca pela alma de Beatriz), lutar e vencer Caronte, guardião dos portões.

0 resumo da história do videogame Dante's Inferno confirma que, para salvar Beatriz, foi necessário que Dante percorresse os nove círculos do inferno, lutasse e derrotasse muitos inimigos para, finalmente, cumprir o seu programa narrativo principal. Podemos concluir, baseados em informações da história do jogo, que Dante teve de enfrentar muitos opositores, mas, de modo especial, um deles, Lúcifer, com quem teve de disputar o mesmo objeto de valor. Se Dante assume, na narrativa, o papel actancial de sujeito, o seu oponente, Lúcifer, é o antissujeito.

Entre adentrar no inferno e salvar Beatriz, Dante teve de adquirir as competências modais para fazê-lo. Poderíamos dizer que ele passou do estado do querer e teve de ser investido de categorias modais que o permitissem realizar a sua performance: possuir um saber (conhecer o caminho para chegar a cada círculo e seus desafios; saber lutar, usar as armas com precisão, dar os golpes exatos, encontrar relíquias que permitissem upgrades para aumentar as suas habilidades de luta); e um poder (vencer os seus opositores).

Importante observar, em narrativas de videogames, que algumas categorias modais, requeridas aos protagonistas, são também exigidas do jogador, o que significar dizer que o jogador, como avatar, um sujeito debreado, deve ter um saber para que Dante possa cumprir a sua performance. 
Em relação ao saber-fazer em Dante's Inferno, o caminho é orientado por Virgílio, o seu adjuvante, que "contribui com o seu auxílio para a realização do programa narrativo do sujeito" (GREIMAS; COURTÉS, 2008, p. 23), ele sabe em que consiste cada círculo, quem são os seus guardiões, os poderes de cada um, os perigos aos quais Dante iria se submeter, e o instrui, ajuda-o, investe-o de um saber-fazer para enfrentar os inimigos. Todos os outros saberes, que estão diretamente relacionados ao jogo, e não à história, são requeridos do jogador: ele precisa saber usar as armas, encontrar as relíquias para aumentar as habilidades de Dante. Nesse sentido, é o jogador, como sujeito debreado, que investe o Sujeito Dante de um saber.

No círculo do Limbo, por exemplo, há uma porta que só pode ser aberta com os monstros explosivos. 0 jogador terá de agarrar os monstros e jogá-los contra a porta, mas, para pegá-los, deve apertar R2 e apontar com o analógico em direção à porta. Para vencer Minós, deve saber que o rei irá atacar sempre que caminhar para trás e permanecer em posição ereta. Para fugir aos ataques, Dante terá de ficar em movimento e atacar Minós na barriga, seu ponto fraco, cuidando, porém, para alcançá-lo a partir da diagonal, para não ser atingindo pela língua de Minós.

O poder-vencer, no videogame, estará diretamente relacionado aos saberes do jogador, que investe a personagem de valores modais, bem como dos upgrades que obtém durante o jogo. Absolvendo ou condenando almas, Dante aumenta as suas habilidades sagradas, que favorecem os ataques a distância e preservam energia, enquanto as profanas fortalecem os ataques com a foice, além das relíquias que encontra ao longo do caminho do inferno e que podem agregar benefícios.

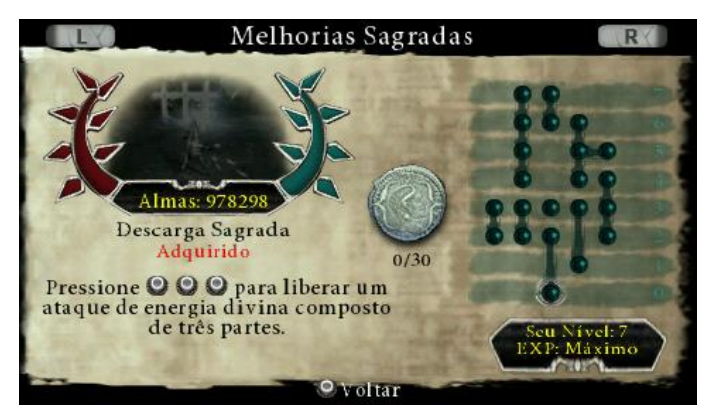

Figura 2: Melhorias sagradas.

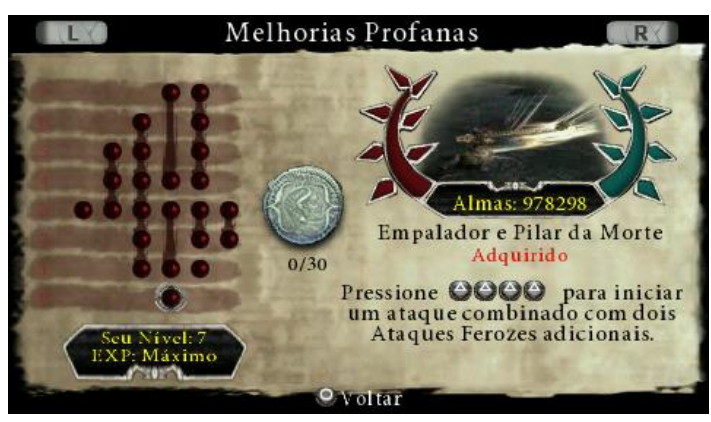

Figura 3: Melhorias profanas.

O dever-fazer, dentro da narrativa, desenvolver-se-á segundo o 
desencadeamento de ações. Ao longo da história, Dante conscientiza-se da sua culpa na morte de Beatriz, e isso resultará como um dever seu de salvá-la, como aprofundaremos ao analisarmos as paixões.

Mesmo que o sujeito operador coincida com a personagem Dante, não podemos confundir sujeito com atores, pois o sujeito é um papel actancial, um lugar que ele ocupa dentro do programa narrativo.

Greimas e Courtés (2008, p. 21), sobre o conceito de actantes, asseveram:

0 conceito de actante substitui com vantagem, mormente na semiótica literária, o termo personagem, e também "dramatis persona", visto que cobre não só seres humanos, mas também animais objetos e conceitos. Além disso, o termo personagem é ambíguo pelo fato de corresponder, também, em parte, ao conceito de ator (em que se pode realizar um sincretismo de actantes) definido como a figura e/ou lugar vazio onde se investem tanto as formas sintáticas como as formas semânticas.

Em Dante's Inferno, Beatriz é o objeto de valor de Dante, mas é uma pessoa, não uma coisa. Ao contrário, o inferno é o destinador que manipula o sujeito para ser-visto, e não é uma pessoa. Assim como em um enunciado existem relações de concordância, de subordinação e de ordem, que definem se os termos exercem uma posição nuclear ou adjunta, analogamente, os papéis actanciais dos atores dos textos vão definir a sua função (sujeito destinador; sujeito operador; sujeito julgador; objeto de valor; antissujeito).

Na sintaxe narrativa, que é organizada a partir de enunciados, podemos depreender dois tipos de enunciados elementares: os enunciados de estado e os enunciados de fazer. Os enunciados que revelam uma relação de conjunção entre sujeito e objeto são chamados de enunciados de estado. Em "Dante é um cruzado", há uma relação de conjunção indicada pelo verbo ser, entre o sujeito "Dante" e um objeto "cruzado". Os enunciados que demonstram a transformação de um estado inicial a um estado final são chamados de enunciados de fazer.

Os enunciados de estado podem, ainda, caracterizar narrativas de privação ou de liquidação. Quando Lúcifer perde o seu lugar no paraíso, ele passa de um estado de conjunção com o objeto "paraíso" para um estado de disjunção com ele. Isso configura, portanto, um programa de privação. Na liquidação, acontece justamente o oposto. Em "Dante salva Beatriz", há uma situação inicial de disjunção com o objeto de valor "Beatriz", seguida da liquidação da privação, que instaura um estado de conjunção com o objeto de valor.

Os textos, no dizer de Fiorin (2009), são narrativas complexas nas quais se 
articulam enunciados do ser e do fazer, hierarquicamente organizados. As narrativas complexas compreendem quatro fases: a manipulação, a competência, a performance e a sanção. 0 sujeito é manipulado a querer ou dever fazer algo, possui uma competência (um saber ou um poder), realiza a sua performance e recebe do sujeito manipulador uma sanção, um julgamento de valor.

Na fase da manipulação, há uma ação de um sujeito sobre o outro para leválo a querer/dever fazer algo. Na narrativa digital que estamos analisando, a decepção é o sujeito que manipula Beatriz a querer vingar-se de Dante. Os quatro tipos mais comuns de manipulação são a tentação, a intimidação, a sedução e a provocação. Na primeira, o manipulador oferece ao manipulado uma recompensa, é uma troca, que o leva a querer fazer algo; na segunda, o sujeito quer fazer algo, porque sofre uma ameaça do manipulador; na terceira, o sujeito é levado a fazer algo após ter recebido um julgamento positivo do manipulador; na quarta, o sujeito é levado a fazer algo, em função de um julgamento negativo do manipulador.

Na fase da competência, o sujeito, para realizar a sua transformação, deve ser dotado de um saber e/ou de um poder. Nos videogames, por exemplo, o poder vencer o jogo está relacionado com um saber ultrapassar as fases. 0 sujeito da narrativa, muitas vezes, tem associado ao seu poder vencer um objeto mágico. Em Dante's Inferno, a cruz de Beatriz e a foice da Morte são objetos que dão ao sujeito Dante a possibilidade de lutar e vencer os seus opositores.

Nas duas fases analisadas, a da manipulação e a da competência, verifica-se que há a modalização do ser pelo querer, dever, poder e saber. Outra perspectiva de análise assumida pela semiótica, mais tardiamente, diz respeito à modalização veridictória que, de certo modo, está em relação com o julgamento da performance do sujeito e a sanção aplicada a ele.

A palavra "veridictório" tem relação com verídico, “[...] que diz ou expressa a verdade" (HOUAISS, 2009). As modalidades veridictórias remetem ao julgamento do sujeito ou do destinador em relação a um estado. As modalidades veridictórias, de acordo com Barros (2008, p. 45, grifos da autora), “[...] articulam-se como categoria modal, em /ser/vs. /parecer/".

No momento da manipulação e da sanção, é realizada a análise do ethos do outro, isto é, o sujeito operador analisa se o sujeito (destinador ou manipulador), ou sua mensagem, é verdadeiro, falso, mentiroso ou secreto (FIORIN, 2009). Se ele 
julgar que o destinador é verdadeiro, aceitará o contrato fiduciário e poderá cumprir a sua performance, se não, poderá rejeitar a manipulação. A mesma análise é realizada pelo destinador julgador em relação às ações realizadas pelo sujeito operador. Essa oposição entre ser x parecer é articulada no quadrado semiótico:

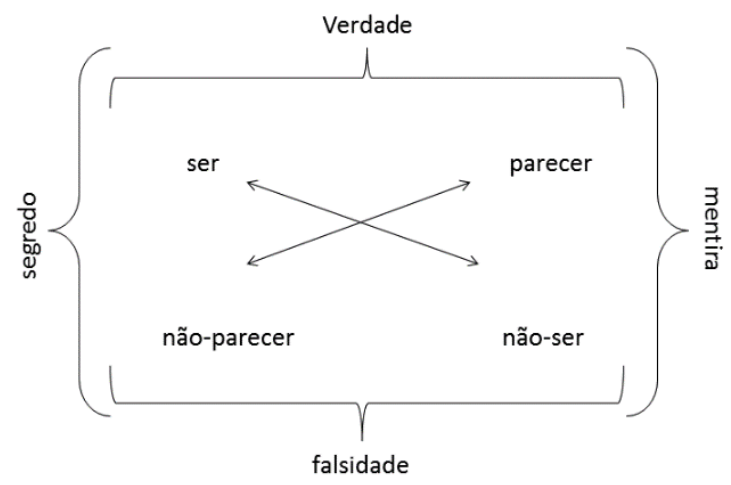

Figura 2: Oposição /ser/ vs. /parecer/.

Fonte: Greimas e Courtés (2008, p. 532).

Sobre a articulação do ser vs. parecer, Greimas (1977, p. 184) explica que:

A sobredeterminação dos atuantes segundo esta categoria do ser e do parecer dá conta desse extraordinário 'jogo de máscaras', feito de afrontamentos de heróis ocultos, irreconhecidos e reconhecidos, e de traidores disfarçados, desmascarados e punidos, que constitui um dos eixos essenciais do imaginário narrativo.

Mesmo que Greimas (1977) afirme que essas categorias do ser vs. o parecer oferecem a possibilidade de analisar o "jogo de máscaras”, é importante notar que tanto o sujeito operador quanto o destinador, respectivamente, ao analisarem a manipulação, ao aplicarem a sanção, agirão segundo seu sistema de valores, as suas crenças.

Na performance, acontece a mudança de um estado do sujeito a um outro, por exemplo: libertar Beatriz das garras de Lúcifer e sair do inferno é a performance de Dante. Nessa fase, o sujeito passa de estado de disjunção à conjunção com o seu objeto de valor (se for um programa narrativo de aquisição) ou de conjunção à disjunção (se for um programa de privação).

A sanção é o momento em que o sujeito, tendo realizado ou não a sua performance, é julgado pelo destinador julgador, que interpreta as ações do sujeito, segundo o contrato inicial, e julga-o positivamente, distribuindo recompensas, ou negativamente, distribuindo castigos. A sanção pode ser pragmática ou cognitiva: 
na cognitiva, o destinador julgador aplica uma sanção baseada em elogios ou humilhações; na pragmática, trata-se de adquirir ou perder, bens ou coisas, sofrer um castigo físico ou a privação de algo.

Fiorin (2009) precisa que, embora a narrativa canônica apresente as quatro fases, como foram apenas descritas (manipulação, competência, performance e sanção), é importante notar que elas não aparecem necessariamente apresentadas nessa ordem. 0 enunciador do texto, de acordo com o seu objetivo, pode antecipar essas fases.

A narrativa Dante's Inferno é complexa, como vimos, e não pode resumir-se em um único programa narrativo, porque é organizada como uma série de subprogramas hierarquicamente organizados. Ao programa principal, também denominado programa de base, estão relacionados os demais programas de uso, de acordo com o ciclo do inferno em que o protagonista está e o que deverá realizar para passar para a fase seguinte. A trama principal, porém, é estabelecida pelo sujeito destinador (Lúcifer) que manipula o sujeito (Dante) a percorrer os nove círculos do inferno em busca do seu objeto de valor (Beatriz). Esse programa pode ser expresso esquematicamente:

$$
\begin{aligned}
& \mathrm{PN}=\mathrm{F}\left[\mathrm{S}_{1} \rightarrow\left(\mathrm{S}_{2} \cap \mathrm{O}_{\mathrm{v}}\right)\right] \\
& \mathrm{PN}=\mathrm{F} \text { (levar Dante ao inferno) }\left[\mathrm { S } _ { 1 \text { (Lúcifer) } } \rightarrow \left(\mathrm{S}_{2} \text { (Dante) } \cap \mathrm{O}_{\mathrm{v} \text { (Beatriz) })]}\right.\right.
\end{aligned}
$$

Para convencer Dante a ir ao inferno, Lúcifer vai estabelecer um contrato com Beatriz e, com base nele, levá-la ao inferno. 0 programa de base da narrativa é um programa de privação para Dante e de aquisição para Lúcifer, já que ambos disputam o mesmo objeto de valor (Beatriz) ou, pelo menos, é isso que o enunciador destinador quer fazer crer, seja a Dante seja ao enunciatário/jogador. Ele cria um simulacro que os faz crer nisso, mesmo deixando pistas, no decorrer da narrativa, para que o enunciatário possa julgá-lo verdadeiro ou falso; somente na última fase do jogo, quando Dante enfrenta Lúcifer, é revelado o motivo da sua manipulação:

[...] Eu estava ao lado dos anjos, depois ele os criou à sua imagem e semelhança. Vocês, criação imperfeita! Eu deveria me dobrar diante de vocês? [...] Obrigado por ter rompido as correntes de Judeca, observa a sua desgraça e assista à minha fuga para o reino do purgatório e do paraíso. [...] Vou reclamar o meu lugar de direito no paraíso. E a minha 
estrada será facilitada pelo pecado do homem. E os seus, Dante, servirão de base para o meu retorno. E tudo o que é bom desaparecerá do universo para sempre (DANTE'S INFERNO, fase final).

O jogador, enunciatário-interlocutário-sujeito da narrativa, é manipulado, também por meio da narrativa pressuposta, a entrar em conjunção com o seu objeto de valor, ou seja, a finalizar o jogo. Nesse caso, os destinadores são os game designers, que desenvolveram o jogo com o objetivo de manipular o jogador, dando pistas, verdadeiras ou falsas, informações sobre como jogar, negociando pontos, relíquias, poderes e a possibilidade de desbloqueio de habilidades para jogar, com maior desempenho, uma nova partida do jogo.

Para Barros (2008), o nível discursivo é definido como um processo de produção que retoma os elementos sobre os quais se debruça a análise narrativa, dando, porém, relevo para aspectos deixados de lado, naquela abordagem, como as projeções da enunciação no enunciado: os recursos que o enunciador utiliza para manipular o enunciatário, os temas e as figuras. É o nível mais próximo do texto, o mais palpável, "[...] em que as formas narrativas abstratas são revestidas por elementos concretos", como afirma Fiorin (2009, p. 45).

Greimas e Courtés (2008, p. 167) argumentam que “[...] a enunciação é o lugar de exercício da competência semiótica, é ao mesmo tempo a instância da instauração do sujeito (da enunciação)", que se realiza por meio das relações entre o tempo, o espaço e os sujeitos da enunciação e o tempo, o espaço e o sujeito do enunciado, estabelecendo o que os autores definem como embreagem, uma aproximação, e debreagem, um afastamento, produzindo efeitos diferenciados no fazer interpretativo do receptor do discurso.

A enunciação é definida como uma instância de um "[...] eu-aqui-agora” (FIORIN, 2009, p. 56).

Os jogos eletrônicos podem ser narrados em primeira pessoa, em que o jogador enunciatário assume o ponto de vista do sujeito da narrativa (debreagem enunciativa de pessoa), ou em terceira pessoa (debreagem enunciva), como acontece em Dante's Inferno. No entanto, em alguns momentos da narrativa, para aumentar o efeito de interatividade, há também a debreagem enunciativa, e o enunciatário compartilha da visão do sujeito, como, por exemplo, quando Dante deve realizar alguma ação, escalar paredes ou saltar, e não a faz no tempo 
determinado pelo jogo, ou é atingido por algum obstáculo e cai. Há um escurecimento da tela, seguido de um texto verbal, contendo um dos versos da obra de Dante Alighieri, A Divina Comédia, e reinicia-se a fase (Figura 5).

A projeção de pessoa, espaço e tempo, pode ser analisada considerando dois aspetos do videogame:

Do ponto de vista do discurso verbal, há uma alternância da narrativa em terceira pessoa, uma debreagem enunciva, o que cria efeito de objetividade e distanciamento (Figura 6): estão projetados uma pessoa (eles), um tempo (nãoagora, 1191) e um espaço (alhures, a 50 quilômetros de Jerusalém). Porém, há uma predominância da debreagem enunciativa, com recursos de diálogos, narrativa em primeira pessoa, conforme Figuras 7 e 8: estão projetados uma pessoa (tu), um tempo (agora) e um espaço (aqui).

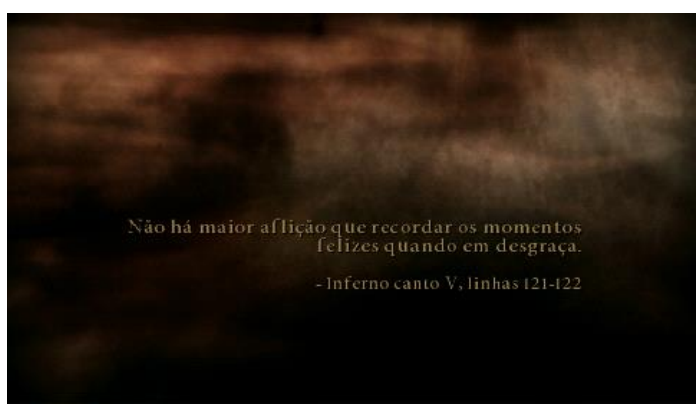

Figura 3: Trecho de A Divina Comédia.

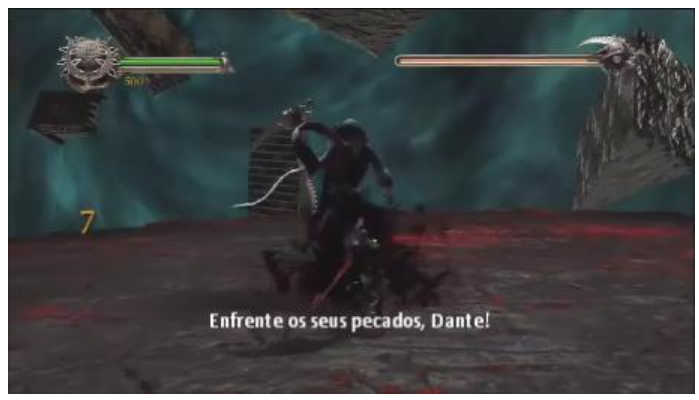

Figura 5: Diálogo da Morte com Dante.

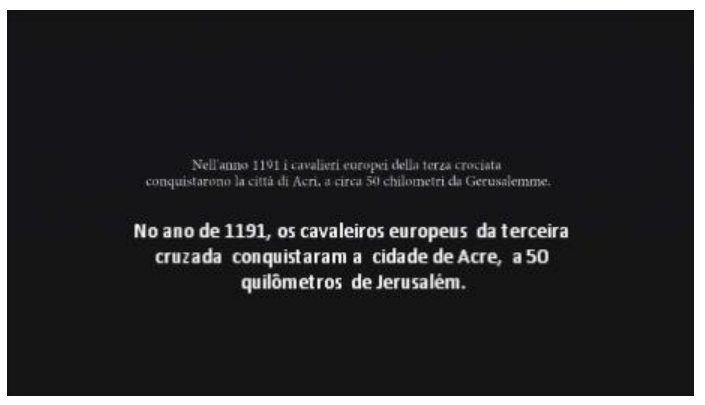

Figura 4: Narração em 3a pessoa.



Figura 6: Narração em 1aㅡ pessoa.

Do ponto de vista da semântica discursiva, os textos são recobertos por temas e figuras. 0 enunciador, para criar um efeito de realidade no texto, seleciona figuras, que recordam algo que existe no mundo natural, como, por exemplo, objetos, pessoas, animais, cores. Os temas presentes no texto recebem investimentos figurativos. 
A narrativa é ancorada em recortes temporais e espaciais, criando um efeito de veracidade. No videogame, isso acontece no plano verbal, por meio do uso dos diferentes tempos verbais, passado, presente e futuro; no plano visual, pela mudança de imagens cinemáticas pré-renderizadas em alta definição (Figuras 9 e 10), cinemáticas in-game (Figura 11) para sequências em animé (Figura 22), com o objetivo de demarcar uma debreagem temporal.

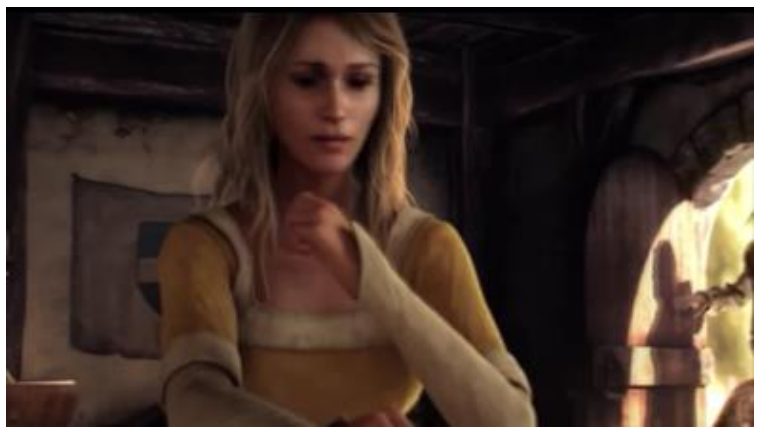

Figura 7: Beatriz, à espera do retorno de Dante.

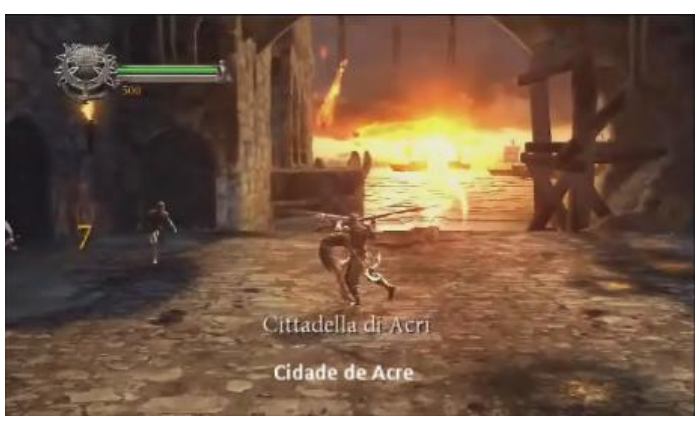

Figura 9: Cidade de Acre.

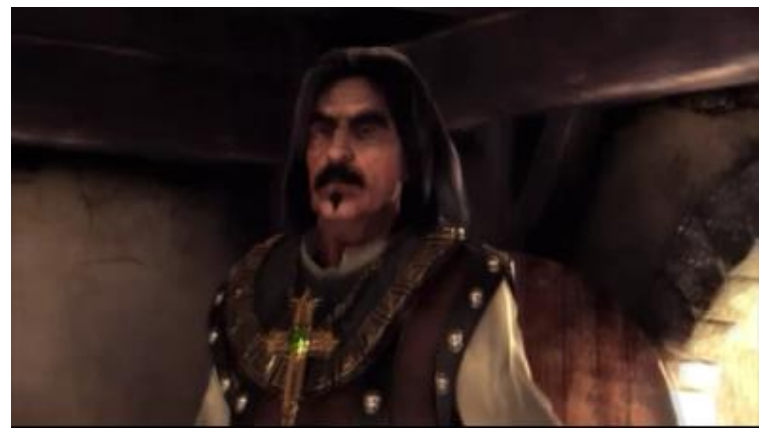

Figura 8: Alighieri.

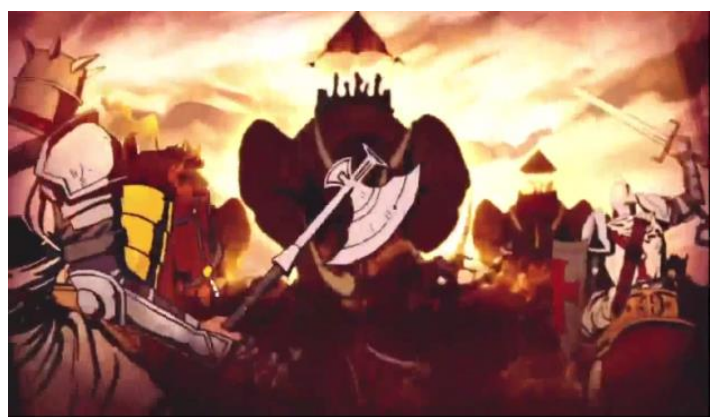

Figura 10: Cidade de Acre.

Na figurativização, o enunciador recobre os percursos temáticos de traços sensoriais. A figura pode ser definida como o "[...] termo que remete a algo existente no mundo natural” (FIORIN, 2009, p. 91). Com investimentos de figuras, criamos discursos figurativos, que "[...] criam um efeito de realidade, pois constroem um simulacro da realidade, representando, dessa forma, o mundo" e que "[...] têm uma função descritiva ou representativa" (FIORIN, 2009, p. 91).

Em Dante's Inferno, é possível identificar alguns percursos figurativos que remetem ao combate, a criaturas e monstros, aos nove círculos do inferno (Limbo; Luxúria; Gula; Avareza; Ira; Heresia; Violência; Fraude e Traição) e às paixões que decorrem dos estados de alma dos sujeitos da narrativa (amor, obstinação, vingança, remorso). 
Os temas podem aparecer de maneira explícita, o que vai depender do gênero em que foi escrito, ou de forma implícita. Portanto, não há, como esclarece Barros (2008), textos sem temas ou figuras; o que pode acontecer é que as figuras apareçam em maior ou em menor grau, dependendo do texto, configurando-o como figurativo ou temático.

Em relação ao espaço, há uma oposição entre interno vs. externo. 0 primeiro remete à selva escura, ao pecado e à morte; o segundo, ao amor de Beatriz (Florença/Itália), marcado pela anterioridade à cruzada; à Cidade de Acre, lugar das cruzadas; à posterioridade à derrota de Lúcifer, um espaço caracterizado pelo recomeço. Dante caminha por uma via subterrânea guiado por Beatriz, que o conduz ao outro lado da terra, já com os pecados purgados. Essa nova fase é figurativizada pelo homem nu, sem pecados, e da cruz no peito restam as cinzas. É um espaço caracterizado pela luminosidade, pela visão do céu.

Mesmo que as análises tenham sido feitas separadamente, por uma questão metodológica, com o objetivo de apresentar em síntese o Percurso Gerativo de Sentido, os limites entre os diversos níveis não são tão rígidos como o apresentado, uma vez que estão estreitamente relacionados.

\section{Algumas considerações}

Sob o enfoque do Percurso Gerativo de Sentidos (Greimas, 1979) foram analisados os sentidos mobilizados nos três níveis: o fundamental, a gênese do sentido; o narrativo, organizado do ponto de vista do sujeito; e discursivo, assumido pelo sujeito da enunciação.

No primeiro depreenderam-se as oposições semânticas que remetem ao bem vs. mal; esperança vs. desesperança; repouso vs. movimento, bem como a articulação dessas categorias reiteradas pelo plano de expressão do texto, por meio da análise eidética, cromática e topológica.

No segundo, a partir da análise dos papéis actanciais do sujeito e da sua relação com o objeto de valor, observou-se que Dante's Inferno é uma narrativa complexa, organizada como uma série de subprogramas hierarquicamente organizados, dispostos em relação hipotáxica.

No terceiro, destacou-se como o tempo e o espaço, dentro da narrativa, têm a tarefa de criar um simulacro de veracidade, sublinhando como no caso do 
videogame, isso acontece seja no plano verbal, marcado pelos tempos verbais no passado, presente e futuro, seja no plano visual, pela mudança de imagens cinemáticas in-game para sequências em anime com o objetivo de demarcar uma debreagem temporal.

Enfim, por meio do caminho percorrido, procurou-se elucidar como esse texto organiza-se discursivamente para dizer o que diz, que inclui a manipulação do leitor, do jogador, nesse caso, para fazê-lo cumprir a performance de zerar o jogo, uma vez que, na execução do jogo, pelo sincretismo de papéis entre o sujeito da narrativa de base, Dante e o jogador, enunciatário-interlocutário-sujeito da narrativa vai exigir um sujeito destinador que o modalize pelo "querer" ganhar o jogo.

\section{Referências}

BARROS, D. L. P. Teoria semiótica do texto. 4 ed. São Paulo: Ática, 2008.

COURTÉS, J. Introdução à semiótica narrativa e discursiva. Coimbra: Almedina, 1979.

DANTE'S INFERNO. Austin: Visceral Games, 2010. (Divine Edition).

FIORIN, J. L. Elementos de análise do discurso. 14 ed. São Paulo: Contexto, 2009.

GREIMAS, A. J. Sémantique Structurale. Paris: Larrousse, 1966.

. Du sens: essais sémiotiques. Paris: Éditions du Seuil, 1970.

. Os atuantes, os atores e as figuras. In: CHKLOVSKI, V. O. (Org.). Semiótica narrativa e textual. São Paulo: Cultrix, 1977, p. 179-195.

Prefácio. In: COURTÉS, J. Introdução à semiótica narrativa e discursiva. Coimbra: Almedina, 1979.

; COURTÉS, J. Dicionário de semiótica. São Paulo: Contexto, 2008.

HOUAISS, A. Dicionário eletrônico Houaiss da língua portuguesa. Rio de Janeiro: Objetiva, 2009.

Pietroforte, A. V. Se. Análise textual da história em quadrinhos: uma abordagem semiótica da obra de Luiz Gê. São Paulo: Annablume; Fapesp, 2009.

ROJO, R. H. R. Linguagens Códigos e suas tecnologias. In: BRASIL. Ministério da Educação. Secretaria da Educação Básica. Departamento de Políticas do Ensino Médio. Orientações curriculares do ensino médio. Brasília, 2004.

TEIXEIRA, L. Para uma metodologia de análise de textos verbovisuais. In: OLIVEIRA, A. C.; TEIXEIRA, L. (Orgs). Linguagens na Comunicação: desenvolvimento de semiótica sincrética. São Paulo: Estação das Letras e Cores, 2009. 